\title{
Novel Actions of Oxazolidinones: In vitro Screening of a Triazolyloxazolidinone for Anticonvulsant Activity
}

\author{
Samuel B. Kombian ${ }^{\text {a }}$ Oludotun A. Phillips ${ }^{b}$

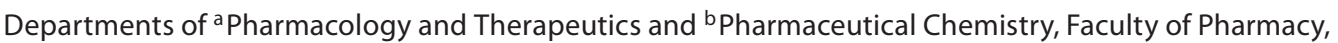 \\ Kuwait University, Safat, Kuwait
}

\section{Key Words}

PH084 • Anticonvulsant activity • In vitro seizure models •

Rat hippocampus

\begin{abstract}
Objective: To test the hypothesis that a triazolyloxazolidinone (PH084) has anticonvulsant activity by examining its effects on in vitro seizure models in the rat hippocampus. Materials and Methods: Whole-cell synaptic currents, action potentials and extracellular population spikes (PS) were recorded in the cell body area of rat hippocampal CA1 region in acutely prepared slices. Chemical [picrotoxin (100 $\mu \mathrm{M})$ and zero magnesium] and electrical seizures were induced and the effect of PH084 (10 $\mu \mathrm{M})$ was tested on cellular responses, multiple spikes and spontaneous bursting frequencies. $\boldsymbol{R} \boldsymbol{e}$ sults: $\mathrm{PH} 084$ depressed evoked excitatory postsynaptic currents, action potential firing frequency and PS amplitude. All of these responses did not recover to baseline after 15-20 min washout of $\mathrm{PH} 084$. Perfusion with zero magnesium ion $\left(\mathrm{Mg}^{2+}\right)$-containing buffer converted a single PS to multiple PS (mPS) accompanied by spontaneous burst. PH084 suppressed the MPS and the spontaneous burst frequency and it also suppressed the picrotoxin-induced mPS number. However, it did not affect the frequency of stimulus traininduced after discharge or bursts. Furthermore, 8-10 min
\end{abstract}

pretreatment with $\mathrm{PH} 084$ did not affect the ability of zero $\mathrm{Mg}^{2+}$ buffer, picrotoxin or stimulus train to induce epileptiform activity. Conclusions: Thus, while PH084 may have potential for anticonvulsant activity against chemically induced seizures, it has little or no potential against electrically induced seizures or in preventing epileptiform discharge.

Copyright $\odot 2012$ S. Karger AG, Basel

\section{Introduction}

The current drug management of epilepsy, a common neurological disorder characterized by recurrent seizures, is not optimal due in part to its complex pathophysiology and/or etiology $[1,2]$. Of particular concern is the fact that a significant proportion of patients (up to $40 \%$ ) do not respond to currently available drugs $[1,3]$. Furthermore, almost all patients on anticonvulsant medications experience some level of unpleasant side effects which affect their quality of life. Thus, the need for continued research into newer, more effective and safer antiepileptic drugs has been advocated $[1,2,4]$ and research activity in this area is intense $[5,6]$ with a new drug, ezogabine (retigabine), entering clinical use quite recently [7] while others are in the pipeline [8].

Samuel B. Kombian

Department of Pharmacology and Therapeutics

Faculty of Pharmacy, Kuwait University

PO Box 24923, Safat 13110 (Kuwait)

E-Mail kombian@hsc.edu.kw 
The hippocampus has a very low seizure threshold and thus the excitatory pyramidal neurons in areas CA1 and CA3 easily develop synchronous depolarization and discharge under disinhibition [9]. Various in vitro models of seizures in hippocampal slices have been used to study seizure phenomena and to test the actions of potential anti-seizure drugs $[10,11]$. These include altering the ionic composition of the artificial cerebrospinal fluid (aCSF) such as lowering calcium ion $\left(\mathrm{Ca}^{2+}\right)$ [12], removing magnesium ion $\left(\mathrm{Mg}^{2+)}\right.$ [13] or blocking $\gamma$-aminobutyric acidA $\left(\mathrm{GABA}_{\mathrm{A}}\right)$ receptors or the chloride channel complex [14]. In addition to these chemical approaches, electrical stimulation [10] using various patterns of stimulation also evokes seizure-like behavior in slices.

We recently screened a series of novel compounds belonging to the oxazolidinone class for neuronal activity and found that some of these compounds had actions consistent with anticonvulsant activity [15]. In this study, we observed that the most neuroactive oxazolidinone, a triazolyl derivative (PH084), depressed N-methyl-D-aspartate (NMDA) and non-NMDA receptor-mediated excitatory postsynaptic currents. Its effect on the latter was blocked by the $\mathrm{GABA}_{\mathrm{B}}$ receptor antagonist CGP55845. Furthermore, it also significantly reduced the action potential firing frequency of hippocampal and accumbens neurons [15]. The current study therefore tested the hypothesis that the most neuroactive oxazolidinone derivative $\mathrm{PH} 084$ has anticonvulsant activity using in vitro seizure models. Here, we report the effects of PH084 on chemically and electrically induced seizures.

\section{Materials and Methods}

\section{Chemicals and Solutions}

All drugs were bath perfused at final concentrations indicated by dissolving aliquots of stock in aCSF. PH084 was synthesized inhouse as previously described [16] and was dissolved in dimethyl sulfoxide (serial dilutions of high concentration stocks resulted in final bath concentrations of $<0.1 \%$ ), aliquoted and frozen at $-20^{\circ} \mathrm{C}$ and used within 2 weeks. All routine laboratory chemicals, tetrodotoxin (TTX) and picrotoxin were purchased from Sigma-Aldrich Chemie GmbH (Steinheim, Germany), while 6,7-dinitro quinoxaline-2,3-dione (DNQX) was obtained from RBI (USA).

\section{Synthesis of $\mathrm{PH} 084$}

The (4-methyl-1H-1,2,3-triazol-1-yl)methyl oxazolidinone PH084 was prepared, purified and characterized using standard analytical methods similar to those previously reported [16].

\section{Animal Experiments}

All the rats used in this study were obtained from the Health Sciences Center, Animal Resource Center, Kuwait University, Ku- wait. All experiments were done in accordance with guidelines on humane handling of experimental animals as established by the Canadian Council on Animal Care. The procedures employed were approved by the Health Sciences Center, Animal Resource Center. All efforts were made to minimize animal suffering, and the minimum number of animals necessary to produce the required results was used.

\section{Slice Preparation}

Thin (350- $\mu \mathrm{m}$ thick) coronal hippocampal slices were generated from male Sprague-Dawley rats (75-150 g) using previously published techniques $[11,17]$. Slices were incubated in aCSF at room temperature $\left(25-26^{\circ} \mathrm{C}\right)$ for at least $1 \mathrm{~h}$ before recording.

\section{Electrophysiological Recording and Data Acquisition}

In vitro extracellular and intracellular responses were recorded using standard electrophysiological recording techniques as previously reported by us and others $[10-15,17]$. Briefly, extracellular recordings were done with $\mathrm{NaCl}(3 \mathrm{M})$-filled glass electrodes (5-15 $\mathrm{M} \Omega$ resistance), while intracellular recording was done with a potassium gluconate-based solution and glass tip resistance of 5.0-10.0 M $\Omega$.

Synaptic responses were recorded by placing a bipolar tungsten-stimulating electrode in the dendritic layer of the CA1 region to activate Schaffer collateral and commissural fibers. Recordings were made using an Axopatch 1D amplifier and pClamp Software (Clampex 8.2; Axon Instruments) in either voltage or current clamp modes. Cells were voltage clamped $\left(\mathrm{V}_{\mathrm{h}}\right)$ at $-60 \mathrm{mV}$ and input $\left(\mathrm{R}_{\text {input }}\right)$ and access $\left(\mathrm{R}_{\mathrm{a}}\right)$ resistances of all cells were determined and monitored regularly throughout each experiment. Wholecell recordings were performed in twelve pyramidal cells in the CA1 region of the rat hippocampus with resting membrane potentials of -59 to $-65 \mathrm{mV}$. All passive and active membrane properties of these cells were similar to those widely reported. Analyses of responses were done as previously reported $[15,16]$.

After a single population spike (PS) was recorded, epileptiform activity was induced either electrically using a pattern of afferent stimulation $[11,17]$ or chemically by bath perfusion of picrotoxin $(100 \mu \mathrm{M})$ or modified buffer containing no $\mathrm{Mg}^{2+}$ with slightly increased potassium $\left(\mathrm{K}^{+}\right)$concentration (total $5 \mathrm{mM}$ ) [1115, 17-22]. Epileptiform activity was defined as multiple spiking ( $>1$ PS) following afferent stimulation and the presence of spontaneous bursts (SBs) without afferent stimulation. In all field experiments, control responses were monitored and shown to be stable for at least $30 \mathrm{~min}$ prior to the application of a drug.

\section{Analysis and Statistics}

The excitatory postsynaptic current (EPSC) amplitude was measured from baseline to peak, while PS amplitude was measured from peak to peak and taken as the response strength at the chosen stimulus intensity. Responses were normalized as previously reported by us $[11,15]$. All values are stated as mean \pm standard error. One-way ANOVA and post hoc paired and unpaired Student's t test, where appropriate, were used to compare different values or treatments using SigmaStat ${ }^{\circledR}$ software (3.5 Edition). Differences between groups were taken as significant at a probability level of $\mathrm{p} \leq 0.05$. Graphing was done using SigmaPlot ${ }^{\circledR}\left(9^{\text {th }}\right.$ Edition; Systat Software Inc., San Jose, Calif., USA) and CorelDraw ${ }^{\circledR}$ (12 ${ }^{\text {th }}$ Edition; Corel Corp., Ottawa, Ont., Canada) software. 


\section{Results}

PH084 Depresses Excitation in the Hippocampus

PH084 at $10 \mu \mathrm{M}$ depressed evoked EPSCs recorded in pyramidal cells of the CA1 region of the hippocampus by $25.4 \pm 10.4 \%(\mathrm{p}<0.05$, paired $\mathrm{t}$ test; $\mathrm{n}=6$; fig. $1 \mathrm{a}, \mathrm{c})$. The EPSC did not recover back to baseline after 15-20 min wash out of PH084. In addition to depressing synaptic responses, PH084 (10 $\mu \mathrm{M})$ also depressed electronically evoked action potential firing frequency in these cells by $42.2 \pm 13.5 \%(\mathrm{p}<0.05$, paired $\mathrm{t}$ test; $\mathrm{n}=6$; fig. $1 \mathrm{~b}, \mathrm{c})$, an effect that did not also reverse during the 15-20 min washing period employed in this study.

\section{Effects of PH084 on Population Responses}

Bath application of $10 \mu \mathrm{M}$ PH084 consistently depressed the amplitude of the PS by $44.2 \pm 10.0 \%$ ( $\mathrm{p}<$ 0.05 , paired t test; $\mathrm{n}=7$; fig. 2). Maximal PS depression was observed after 5-6 min PH084 application and did not recover after 15-20 min washout of PH084. At the end of some of these experiments, application of either TTX (1 $\mu \mathrm{M}$, see fig. 3$)$ or DNQX (10 $\mu \mathrm{M}$, data not shown) completely abolished the PS.

\section{PH084 Reduces the Frequency of Occurrence of \\ Chemically Induced Multiple Spikes and \\ Spontaneous Bursts}

In the presence of picrotoxin, the removal of the strong inhibitory influence of GABA on the CA1 neurons transformed the single PS into multiple PS (3.6 \pm 0.4 spikes; $\mathrm{n}=5)$ reflecting epileptiform activity in these slices. PH084 $(10 \mu \mathrm{M})$ depressed the number of these picrotoxininduced multiple PS by $44.7 \pm 7.0 \%$ ( $\mathrm{p}<0.05$, paired t test; $\mathrm{n}=5$ ). Furthermore, after the development of multiple PS (mPS) to stimulation, the slices also developed SB (independent of stimulation), the frequency of which was also depressed by $37.6 \pm 6.4 \%(\mathrm{p}<0.05$, paired $\mathrm{t}$ test; $\mathrm{n}=3)$.

In the zero $\mathrm{Mg}^{2+}$ model, when $\mathrm{Mg}^{2+}$ was eliminated from the perfusion buffer, the voltage-dependent $\mathrm{Mg}^{2+}$ block of NMDA receptor was removed and epileptiform activity occurred. Similar to the picrotoxin model, after recording in zero $\mathrm{Mg}^{2+}$ buffer for 20-30 min, a single PS was transformed into multiple PS $(5.0 \pm 0.3, \mathrm{n}=7)$ in response to a single electrical stimulation of the afferents. PH084 $(10 \mu \mathrm{M})$ reduced the number of multiple PS to 3.1 \pm 0.5 representing a reduction of $38.7 \pm 8.3 \%(\mathrm{p}<0.05$, paired $\mathrm{t}$ test; $\mathrm{n}=7$; fig. $3 \mathrm{a}, \mathrm{c}$ ). In addition to transforming a single PS to multiple PS, zero $\mathrm{Mg}^{2+}$ also induced SB that occurred without stimulation. The SB frequency under control was $5.8 \pm 1.7 / \mathrm{min}$ and it was reduced to $3.8 \pm$

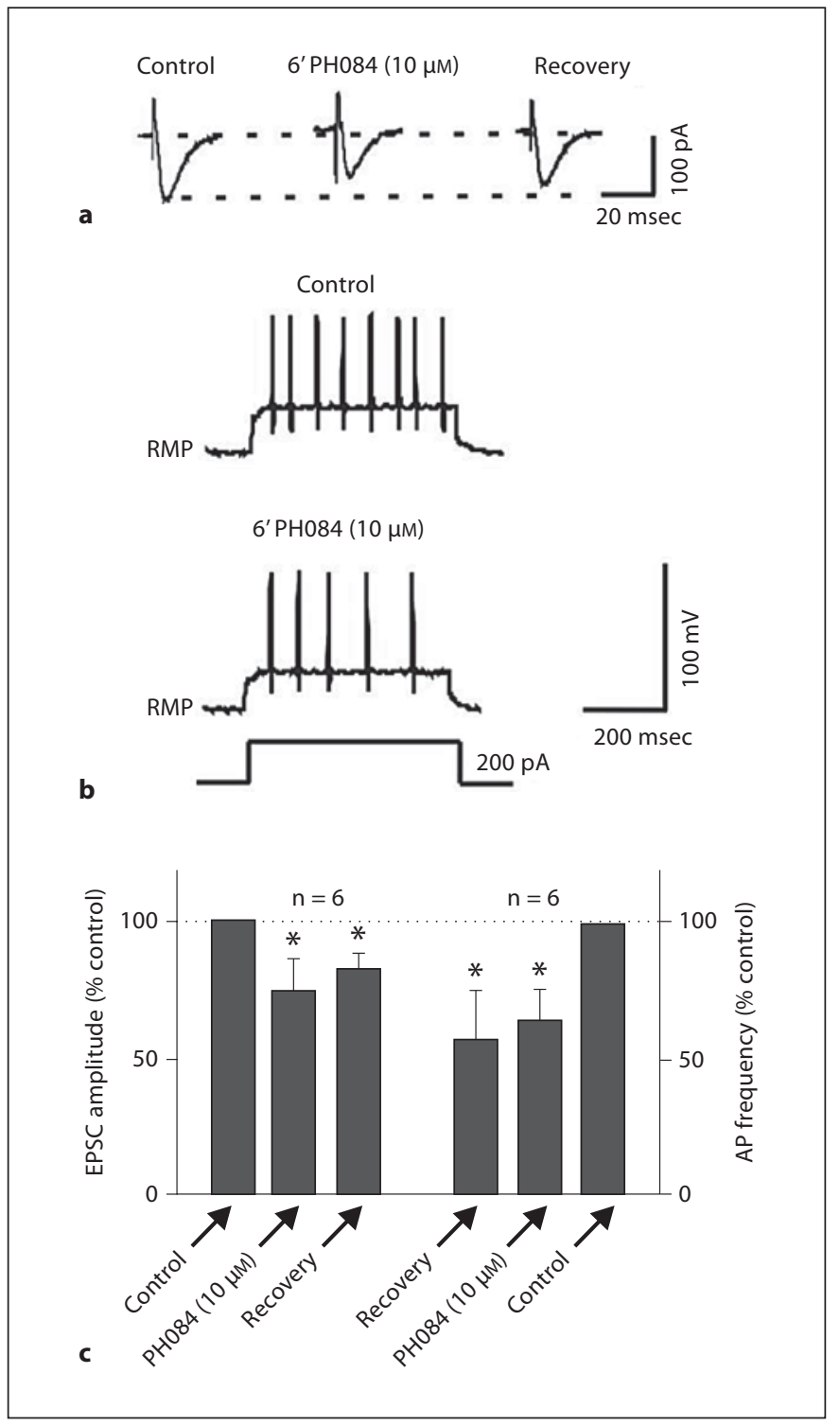

Fig. 1. PH084 depresses evoked EPSC amplitude and action potential firing rate recording in CA1 pyramidal cells. In this figure and in all other figures, ${ }^{*}$ indicates statistical significance at $\mathrm{p} \leq$ 0.05 compared to control.

2.2/min in the presence of PH084 $(10 \mu \mathrm{M})$ representing a reduction in the frequency of occurrence of SBs of $50.7 \pm$ $24.2 \%(\mathrm{p}<0.05$, paired $\mathrm{t}$ test; $\mathrm{n}=6$; fig. $3 \mathrm{~b}, \mathrm{c})$.

\section{PH084 Does Not Affect Electrically Induced Epileptiform Activity}

After recording a stable PS, application of several high frequency stimulation (HFS) was followed by characteristic epileptiform discharges, an initial after discharge 


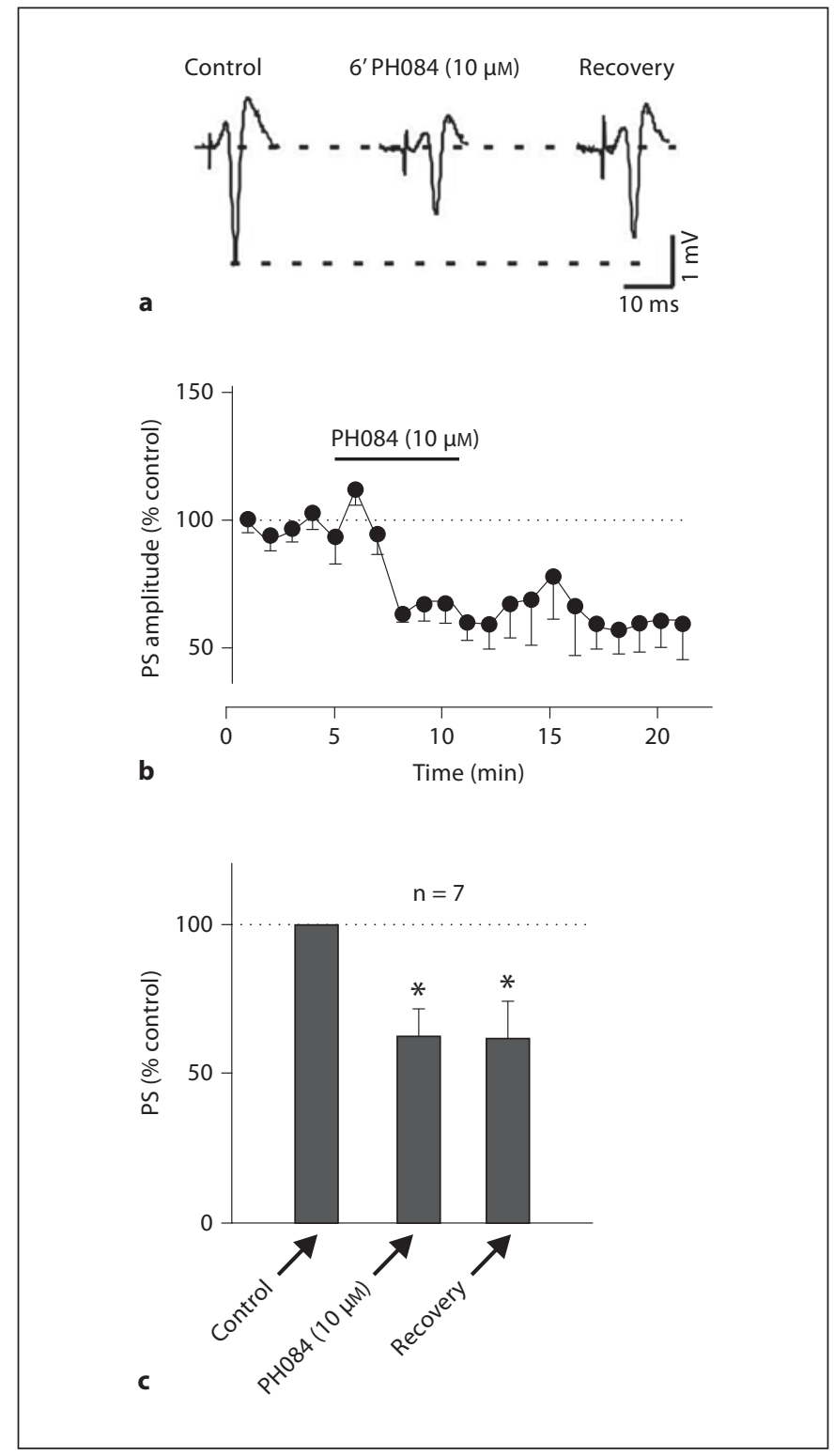

Fig. 2. PH084 irreversibly depresses PS recorded in the cell body layer of the hippocampal CA1 region.

(AD) following the stimulus train and subsequently by $\mathrm{SB}$, referred to as stimulus train-induced bursts (STIBs) in the absence of HFS. When we successfully induced epileptiform activity with HFS in the CA1 area, the AD frequency was $9.1 \pm 0.7 \mathrm{~Hz}(\mathrm{n}=10)$, which was not significantly affected by PH084 $(10 \mu \mathrm{M})$. After 6 min of application, the frequency was $9.4 \pm 0.7 \mathrm{~Hz}$ yielding a change of $4.7 \pm 5.5 \%$ ( $p>0.05$, paired t test; $n=10$; fig. 4 ). STIBs were also unaffected by PH084 (see arrows in fig. 4).

Oxazolidinones as Anticonvulsants

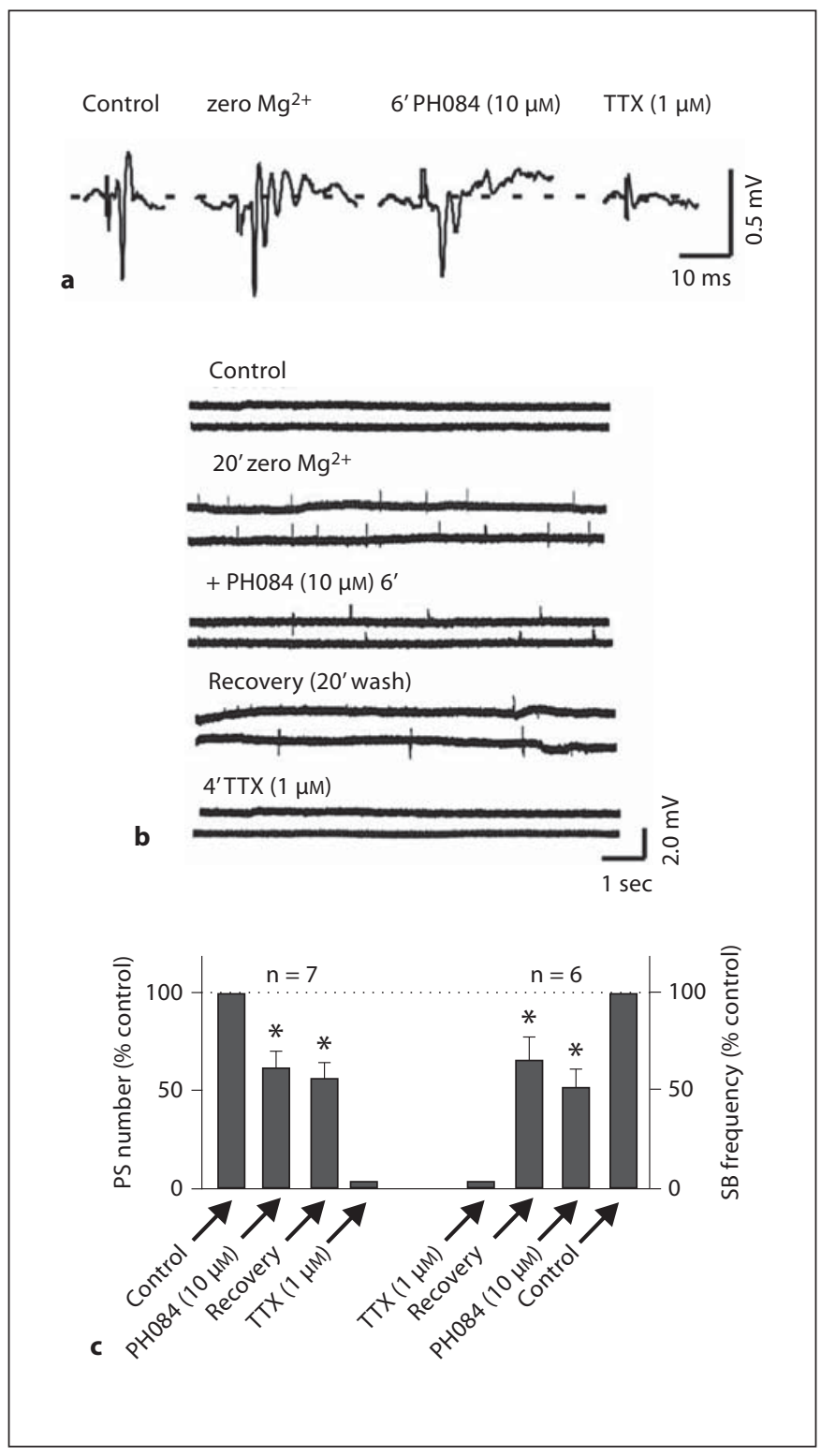

Fig. 3. PH084 depresses zero $\mathrm{Mg}^{2+}$-induced epileptiform activity (mPS and SBs) that is eliminated by TTX.

Pretreatment with PH084 Does Not Prevent the Development of Epileptiform Activity

Bath application of a relatively high concentration (100 $\mu \mathrm{M})$ of PH084 for $10 \mathrm{~min}$, while depressing the PS amplitude by $38.2 \pm 8.9 \%(n=5 ; p<0.05)$, did not change the number of spikes following stimulation $(1.0 \pm 0.0, \mathrm{p}>$ 0.05 compared to control, $\mathrm{n}=5$ ). In the presence of this high concentration of $\mathrm{PH} 084$, zero $\mathrm{Mg}^{2+}$ aCSF was still able to induce mPS $(3.9 \pm 0.6, \mathrm{p}<0.05)$ compared to the 


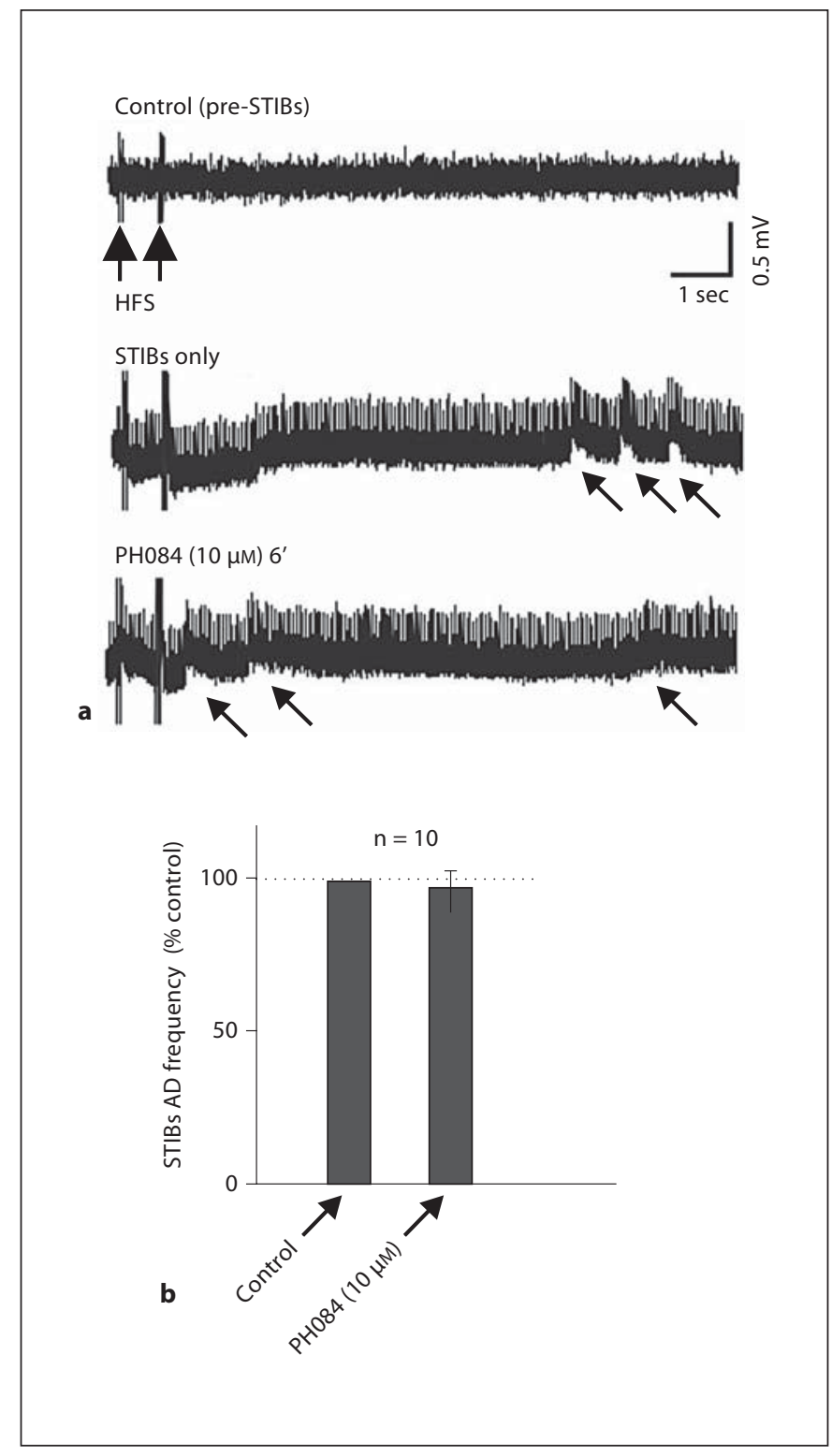

Fig. 4. PH084 does not affect stimulus train-induced ADs and SBs.

single spike in the presence of PH084 alone $(n=5)$. Furthermore, pretreatment with $\mathrm{PH} 084$ did not also produce changes in SB or prevent zero $\mathrm{Mg}^{2+}$ from inducing SB in these slices $(11.0 \pm 1.8 / \mathrm{min}, \mathrm{n}=4 ; \mathrm{p}<0.05$, paired t test). Similarly, pretreatment with PH084 did not prevent picrotoxin from converting single PS to $\mathrm{mPS}(3.3 \pm 0.4$ spikes, $\mathrm{n}=3 ; \mathrm{p}<0.05)$ or stimulus train-induced $\mathrm{AD}(10.2$ $\pm 0.7 \mathrm{~Hz}, \mathrm{n}=5 ; \mathrm{p}<0.05)$.

\section{Discussion}

In this study of the effects of PH084 on epileptiform activity, the concentration of $10 \mu \mathrm{M}$ was chosen because we had previously reported that $\mathrm{PH} 084$ had a concentration-dependent effect on synaptic transmission in the CNS [15], and this concentration was found to produce robust and consistent effects. $\mathrm{PH} 084$ depressed excitatory synaptic transmission and action potential firing in hippocampal CA1 neurons. Furthermore, it inhibited chemically induced seizures in hippocampal slices without affecting electrically induced seizures. In contrast to the above, it did not prevent the development of chemically induced epileptiform activity in hippocampal slices. All these findings suggest that $\mathrm{PH} 084$ may possess anticonvulsant activity against seizures caused by neurotransmitter (chemical) imbalance but has limited utility on those driven by aberration in electrical activity or preventing the development of epileptiform activity.

The observed suppression of chemically induced seizures is consistent with our previous report [15] which showed that the effect of PH084 on excitatory synaptic transmission was inhibited by $\mathrm{GABA}_{\mathrm{B}}, \alpha$-adrenergic and dopamine D1-like receptor antagonists. GABA, noradrenaline and dopamine have all been implicated in the pathophysiology of seizures $[2,23,24]$. Of these transmitters, GABA is the one most studied as it is implicated in the pathophysiology of seizures, and several currently used or under development antiepileptic agents target this transmitter, its receptors or metabolism [8, 25-28]. The blockade of $\mathrm{PH} 084$-induced depression of excitatory synaptic transmission by a $\mathrm{GABA}_{\mathrm{B}}$ receptor antagonist suggests that this compound works in part by modulating GABA transmission in the CNS. Furthermore, the reported inhibition of action potential firing here and in our previous report [15] indicates that PH084 also decreases direct neuronal excitation suggesting that $\mathrm{PH} 084$ uses both synaptic and extra- or post-synaptic mechanisms to depress the excitability of neurons and hence to decrease chemically induced epileptiform activity. The lack of effect on electrically induced epileptiform activity suggests that the predominant action of PH084 to suppress seizure activities is via modulation of synaptic and possibly extrasynaptic transmitter actions. Its inability to prevent the development of epileptiform activity following pretreatment of slices also suggests that the compound only has potential utility in the treatment and not prevention of seizure development in seizure prone individuals or progression of disease in diagnosed epilepsy patients. 


\section{Conclusion}

Given that PH084 has been shown here to depress action potential firing and excitatory synaptic transmission as well as chemically induced epileptiform activity in the hippocampus, a seizure relevant brain region, we suggest that $\mathrm{PH} 084$ and possibly other oxazolidinones are potentially viable novel candidates for the development of new antiepileptic agents. Further structural modifications of PH084 and design and synthesis of new oxazolidinone derivatives may result in the discovery of novel oxazolidinone derivatives that possess increased spectrum of activity against various seizures.

\section{Acknowledgements}

This work was supported by Kuwait University grant No. PT01/10 to S.B.K. We thank Dr K.V.V. Ananthalakshmi for assistance with the experiments.

\section{References}

1 Loscher W: Current status and future directions in the pharmacotherapy of epilepsy. Trends Pharmacol Sci 2002;23:113-118.

2 McNamara JO: Emerging insights into the genesis of epilepsy. Nature 1999;399:A15A22.

-3 Kwan P, Brodie MJ: Early identification of refractory epilepsy. N Engl J Med 2000;342: 314-319.

4 Brodie MJ: Do we need any more new antiepileptic drugs? Epilepsy Res 2001;45:3-6.

5 Pollard JR, French J: Antiepileptic drugs in development. Lancet Neurol 2006;5:10641067.

6 Wuttke TV, Lerche H: Novel anticonvulsant drugs targeting voltage-dependent ion channels. Expert Opin Investig Drugs 2006;15: 1167-1177.

7 Strafstrom CE, Grippon S, Kirkpatrick P: Ezogabine (retigabine). Nat Rev Drug Discov 2011;10:729-730

8 Stephen LJ, Brodie MJ: Pharmacotherapy of epilepsy: newly approved and developmental agents. CNS Drugs 2011;25:89-107.

9 Johnston D, Brown TH: Control theory applied to neural networks illuminates synaptic basis of interictal epileptiform activity. Adv Neurol 1986;44:263-274.

10 Stasheff SF, Bragdon AC, Wilson WA: Induction of epileptiform activity in hippocampal slices by trains of electrical stimuli. Brain Res 1985;344:296-302.

-11 Ananthalakshmi KV, Edafiogho IO, Kombian SB: Anticonvulsant enaminone E139 suppresses epileptiform activity in rat hippocampal slices. Epilepsy Res 2007;76:8592.
12 Jefferys JG, Haas HL: Synchronized bursting of CA1 hippocampal pyramidal cells in the absence of synaptic transmission. Nature 1982;300:448-450.

13 Gean PW, Shinnick-Gallagher P: Epileptiform activity induced by magnesium-free solution in slices of rat amygdala: antagonism by $\mathrm{N}$-methyl-D-aspartate receptor antagonists. Neuropharmacology 1988;27:557562.

14 Traynelis SF, Dingledine R: Potassium-induced spontaneous electrographic seizures in the rat hippocampal slice. J Neurophysiol 1988;59:259-276.

15 Kombian SB, Phillips OA: In vitro electrophysiological investigations of the acute effects of linezolid and novel oxazolidinones on central nervous system neurons. Neuroscience 2011;180:53-63.

-16 Phillips OA, Udo EE, Abdel-Hamid ME, Varghese R: Synthesis and antibacterial activity of novel 5-(4-methyl-H1-1,2,3-triazole)methyl oxazolidinones. Eur J Med Chem 2009;44:3217-3227.

- 17 Kombian SB, Ananthalakshmi KV, Edafiogho IO: Norepinephrine and E139 interactions on epileptiform activity in the rat hippocampus in vitro. Med Princ Pract 2008; 17 : 365-372.

18 El Bahh B, Balosso S, Hamilton T, Herzog H, Beck-Sickinger AG, Sperk G, Gehlert DR, Vezzani A, Colmers WF: The anti-epileptic actions of neuropeptide $\mathrm{Y}$ in the hippocampus are mediated by $\mathrm{Y}$ and not $\mathrm{Y}$ receptors. Eur J Neurosci 2005;22:1417-1430.

19 Uruno K, O’Connor MJ, Masukawa LM: Alterations of inhibitory synaptic responses in the dentate gyrus of temporal lobe epileptic patients. Hippocampus 1994;4:583-593.
20 Mayer ML, Westbrook GL: Permeation and block of N-methyl-D-aspartic acid receptor channels by divalent cations in mouse cultured central neurones. J Physiol 1987;394: 501-527.

21 Wong BY, Prince DA: The lateral spread of ictal discharges in neocortical brain slices. Epilepsy Res 1990;7:29-39.

22 Gulyas-Kovacs A, Doczi J, Tarnawa I, Detari L, Banczerowski-Pelyhe I, Vilagi I: Comparison of spontaneous and evoked epileptiform activity in three in vitro epilepsy models. Brain Res 2002;945:174-180.

23 Kaminski RM, Shippenberg TS, Witkin JM, Rocha BA: Genetic deletion of the norepinephrine transporter decreases vulnerability to seizures. Neurosci Lett 2005;382:51-55.

24 Loscher W, Schmidt D: New horizons in the development of antiepileptic drugs. Epilepsy Res 2002;50:3-16.

25 Wahab A, Albus K, Gabriel S, Heinemann U: In search of models of pharmacoresistant epilepsy. Epilepsia 2010;51:154-159.

26 Macdonald RL, Kang JQ, Gallagher MJ: Mutations in GABAA receptor subunits associated with genetic epilepsies. J Physiol 2010; 588:1861-1869.

27 Schousboe A, Madsen KK, White HS: GABA transport inhibitors and seizure protection: the past and future. Future Med Chem 2011; 3:183-187.

28 Mula M: GABAergic drugs in the treatment of epilepsy: modern or outmoded? Future Med Chem 2011;3:177-182. 